\title{
FREQUENCY AND ETIOLOGICAL DISTRIBUTION OF GENITAL INFECTIONS IN CHILDREN WITH TYPE 1 DIABETES
}

\author{
Stanimira Elkina ${ }^{1}, V$ alentina Popova ${ }^{2}$, Chayka Petrova $^{1}$, Venetsiya Botsova $^{1}$ \\ ${ }^{1}$ Department of Pediatrics, Medical University - Pleven \\ ${ }^{2}$ Department of Microbiology, Virology and Medical Genetics, Medical University - Pleven
}

\begin{abstract}
Purpose: To determine the frequency and etiological distribution of genital infections among children and adolescents with T1D in the Pleven region.

Material: The study was performed at the Department of Pediatrics, University Hospital -Pleven. It involved 78 patients ( 33 boys and 45 girls) with T1D at the age of $11.9 \pm 0.8$ years, admitted from March 2013 to March 2014. They were on an intensive insulin therapy with recombinant human insulin or analog insulins.

Methods:

* An inspection of the external genitalia for signs of inflammation.

* Microbiological testing of genital discharge.

* Glycosylated hemoglobin $\left(\mathrm{Hb}_{\mathrm{Alc}}\right)$ for assessment of metabolic control.

Results: Out of the 78 studied children, 34 (43.5\%) had clinical signs of genital infection (GI). The mean level of their $\mathrm{Hb}_{\mathrm{Alc}}$ was $11.25 \pm 0.65 \%$. Positive cultures were found in $28 / 78(36 \%)$. Most GI were caused by fungi - in 15/28 cases, followed by bacteria $-9 / 28$ and mixed fungal-bacterial flora in $4 / 28$ cases. The main fungal pathogens cultured was Candida albicans in 10/15 cases, followed by Candida tropicalis - in 3/15.

Bacteria were presented by Streptococcus agalactiae in $3 / 9$ cases, Enterococcus faecalis $-3 / 9$, Staphylococcus aureus - 2/9 and Escherichia coli in only 1 child.

Conclusions: Our data confirm badly controlled T1D as a predisposing factor for genital infections in children, predominantly with Candida albicans, which can sometimes be associated with bacterial pathogens. This requires external genitalia inspection and microbiological testing for early diagnosis, and adequate treatment to prevent further complications.
\end{abstract}

Keywords: children, Type 1 diabetes, genital infections, frequency, etiology

Address for correspondence:

Stanimira Elkina, MD

Department of Pediatrics,

UMHAT " Georgi Stranski"- Pleven,

Medical University - Pleven

8 A Georgi Kochev Str.

5800 Pleven, Bulgaria

e-mail:st_elkina_bg@abv.bg

phone: 064/ 886506

Received: May 14, 2014

Accepted: September 10, 2014

\section{INTRODUCTION}

Type 1 diabetes (T1D) is a chronic metabolic disease characterized by deficiency of insulin secretion, lack of insulin action or both (6). The disease frequency is constantly increasing in all ages. Moreover, T1D is a risk factor for severe long term vascular complications. In addition, T1D increases the risk of common infections. This is associated with impaired immune response due to reduced neutrophil function, decreased response of T-cells and low levels of 
some leukotrienes and prostaglandin E. The immunological defects in combination with hyperglycemia and persistent glucosuria are considered as risk factors for genital infections (GI) in patients with T1D $(1,4,5,11)$.

Some clinical studies have shown that genital infections in diabetic patients are more severe, often have unusual manifestation and last longer. They are also more difficult to treat (9). There is limited data on this problem for the Bulgarian population.

The aim of this study is to determine the frequency and etiological distribution of genital infections among children and adolescents with T1D in the Pleven region.

\section{MATERIAL AND METHODS}

The study was performed at the Diabetes Unit, Department of Pediatrics at University Hospital Pleven and involved patients admitted for a period of one year, from March 2013 to March 2014. It was approved by the Ethical Committee of Medical University - Pleven.

We studied 78 children ( 33 boys $-42.3 \%$ and 45 girls $-57.7 \%)$ with T1D at the age of $11.9 \pm 0.8$ years and mean diabetes duration of $3.6 \pm 0.9$ years, who were on an intensive insulin therapy with recombinant human or analog insulins. The diabetes was diagnosed according to the ISPAD's 2009 criteria.

An inspection of the external genitalia was conducted for signs of inflammation.

Microbiological testing of genital discharge was performed. Sterile cotton-tipped swabs were used to collect samples of discharge from the genitalia. The swabs were immediately sent to the Microbiology laboratory at University Hospital - Pleven for direct microscopical examination and cultures. Cultures were made onto blood agar, Sabouraud's agar and on chromogenic $\mathrm{BBL}^{\mathrm{TM}} \mathrm{CHROMagar}{ }^{\mathrm{TM}}$ Candida Medium (Becton Dickinson). The cultures were incubated at $37^{\circ} \mathrm{C}$ for $24-48$ hours. The isolated bacterial pathogens were identified by conventional methods and by the automated system VITEK 2 compact (bioMerieux).

Fungal identification was based on microscopical examination, growth characteristics and the VITEK 2 compact system. Candida albicans was differ- entiated by its ability to form germ tubes, pseudohyphe and chlamydospores.

Blood samples were taken for assessment of metabolic control of T1D. Glycosylated hemoglobin $\left(\mathrm{Hb}_{\mathrm{AlC}}\right)>7.5 \%$ was considered as a sign of poor metabolic control.

Statistical analysis was performed using STATGRAPHICS; SPSS and EXCEL for Windows.

\section{RESULTS}

The frequency of GI in the children from the study group was evaluated. Out of the 78 studied diabetic children, 34 (43.5\%) had clinical signs of GI. They had medical history of burning and itching, and inspection of their external genitalia revealed pathological discharge, edema and hyperemia. The mean level of their $\mathrm{Hb}_{\text {Alc }}$ was $11.25+/-0.65 \%$, significant higher than in children without GI $-9.10+/-$ $0,69 \%(\mathrm{p}<0.05)$.

Symptoms of GI were found as well in children with long term diabetes as in newly diagnosed patients. The mean diabetes duration of children with GI (3.9+/-1.2 years) was longer than of children without GI $(3.4+/-0.8)(\mathrm{p}<0.05)$.

Out of the all 78 patients with T1D, $50(64 \%)$ had negative cultures. Symptomatic GI, but negative cultures was observed in $6 / 78$ patients. No signs of GI and negative cultures were found in 44/78 diabetic children.

Positive cultures were found in 28/78 (36\%) of the cases all symptomatic. Fungal pathogens were isolated in $15 / 78(19 \%)$ of the patients, bacteria in 9/78 (12\%), and mixed flora (fungal and bacterial pathogens) was established in $4 / 78$ (5\%) of the diabetic children with GI (Fig. 1).

Among the children studied, genital infections were found to be more frequent in girls $-20 / 34$



Fig. 1. Genital infections in children with type 1 diabetes 
Stanimira Elkina, Valentina Popova, Chayka Petrova et al.

(58.8\%). In 16/20 positive cultures were found, predominantly yeast infections $-10 / 16$. The distribution of GI by gender and etiology is shown on Table 1 .

\section{DISCUSSION}

The results of the study revealed that almost one half of the researched children with T1D had

Table.1. Prevalence of genital infections by gender and etiology $(N=28)$

\begin{tabular}{lc|c|c|c|c|c|} 
& \multicolumn{2}{c|}{ Fungal } & \multicolumn{3}{c|}{ Bacterial } & \multicolumn{2}{c|}{ Mixed } \\
Gender & $\mathrm{n}$ & $\%$ & $\mathrm{n}$ & $\%$ & $\mathrm{n}$ & $\%$ \\
Female & 10 & 35,7 & 5 & 17,9 & 1 & 3,6 \\
Male & 5 & 17,9 & 4 & 14,2 & 3 & 10,7 \\
Total & 15 & 53,6 & 9 & 32,1 & 4 & 14,3 \\
\hline
\end{tabular}

All fungal pathogens cultured in the patients from the study group belonged to the Candida species. Candida albicans was the most frequently isolated type, found in 10/15 of the cases, followed by Candida tropicalis in $3 / 15$, and the remaining $2 / 15$ cases were caused by both species: C. albicans and C. tropicalis.

The bacterial pathogens isolated in the patients with GI were predominantly Gram positive microorganisms: Streptococcus agalactiae occurred in 3/9 cases, Enterococcus faecalis was also found in 3/9, and Staphylococcus aureus in 2 of the patients. Gram negative bacteria (Escherichia coli) were isolated in only 1 child.

Mixed flora was found in 4/28 of the GI. C. albicans was isolated in association with Staphylococcus aureus in 2, Staphylococcus epidermidis in 1 and Streptococcus agalactiae in 1 of the cases.

The etiological structure of the microorganisms encountered in GI among the children in the study group is shown on Fig. 2.
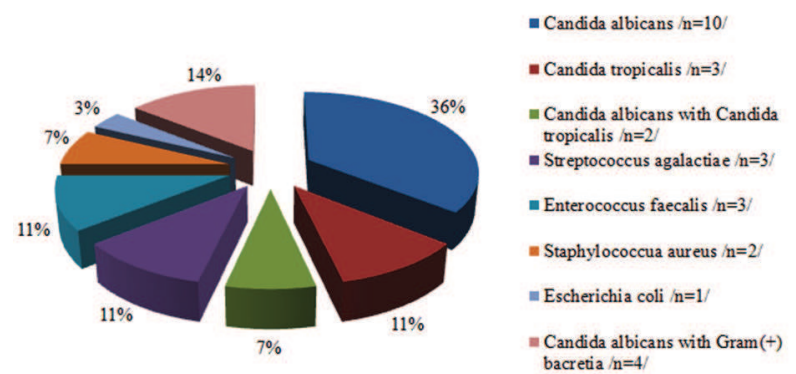

Fig.2. Etiological distribution of the microorganisms encountered in genital infections clinical signs of GI. In most of the cases the infection was caused by yeast pathogens.

Females were infected slightly more often than males. The results confirmed the data from other similar studies, which suggest that genital candidiasis is more prevalent in girls and women with diabetes $(1,2,3,7)$. One of the reasons for this is the anatomical position of the female external genitalia and the anal region. Additionally, poor hygiene habits and tight underwear can facilitate the spread of infections (11).

The results of the study also confirm that T1D increases the risk of GI. Research suggests that long term hyperglycemia decreases the functions of neutrophils, monocytes and macrophages. It can also impair the phagocytosis, chemotaxis and the T-cells' response. Some local factors are also considered as predisposition for GI in diabetic patients. For instance, high glucose level in genital tissues, caused by glucosuria, decreased blood flow and damaged nerves facilitate pathogens' invasion $(1,7,10)$.

The current study is also consistent with past research, suggesting that GI in patients with T1D are predominantly caused by Candida species. However, there are controversial data in the literature on the distribution of different Candida types. Many researchers indicate that Candida albicans is the most frequently isolated fungal pathogen among the diabetic children with GI. Nevertheless, a growing frequency of non-albicans infections has been observed in the last decades $(1,2,3,7)$. One our previous research (Petrova Ch. et al., 2004) confirmed prevalence of non-albicans genital candidiasis among children with T1D (11). In the current study group, GI 
are most often due to C. albicans, and in a few cases to C. tropicalis.

Literature also suggests that C. albicans colonizes the skin and mucosa of $30-70 \%$ of healthy people and does not lead to diseases. But in cases of impaired immune response (diabetes, HIV, tumors) it can cause an infection. Past research suggests that long term hyperglycemia catalyzes the expression of proteins on Candida albicans surface, which are homologous to complement (C3) receptors. C3 receptors cannot recognize the Candida as a pathogen. This process of mimicry facilitates the initiation of infection $(7,8)$.

Some studies indicate that GI in patients with T1D can be caused by Gram positive bacteria or by mixed flora (fungal and bacterial pathogens) (11). In one third of our patients the genital infection is due to Gram positive microorganisms, which confirms data from the literature. In a few of the children from the current study, Gram positive bacteria are found in association with C. albicans.

Poor long-term metabolic control was observed among children with T1D who developed GI, as shown by their high mean level of $\mathrm{Hb}_{\mathrm{Alc}}$. Our study considers both - poor metabolic control and diabetes duration as risk factors for infection's developing. There are inconclusive data in the literature on the association between the level of $\mathrm{Hb}_{\mathrm{Alc}}$ and frequency of GI $(1,7)$. Further research in this field could explore this relationship.

\section{CONCLUSION}

The study shows that genital infections are a serious health problem in children with T1D who have poor metabolic control.

T1D is shown as a predisposing factor for genital infections in children, predominantly with Candida albicans, which can sometimes be associated with bacterial pathogens.

We recommend that external genitalia inspection and microbiological cultures of genital discharge become an obligatory part of the examination of children with T1D. This way, an early diagnosis and adequate treatment of GI can be provided. Severe complications could be reduced and long-term metabolic control could be improved.

\section{Acknowledgement:}

This study was supported by project № D1/2014

of Medical University of Pleven, Bulgaria

\section{REFERENCES}

1. Al-mamari A, M Al-burhi, S Al-hag. Species-specific prevalence of vaginal candidiasis with type 1 and type 2 diabetes mellitus among women in Sana’a city. J. Chem. Pharm. Res., 2013;5(8):217-224.

2. Atabek M, N Akyurek, BS Eklioglu. Frequency of Vaginal Candida Colonization and Relationship between Metabolic Parameters in Children with Type 1 Diabetes Mellitus. J Ped.Adol.Gyn, 2013;26(5):257-260.

3. Bohannon N. Treatment of Vulvovaginal Candidiasis in Patients with Diabetes. Diabetes Care, 1998;21(3):451-456.

4. Casqueiro J, J Casqueiro, C Alves. Infection in patients with diabetes mellitus: A review of pathogenesis. Indian J Endocrinol Metab., 2012;16(Suppl. 1):27-36.

5. Chiţa T, M Licker, A. Sima et al. Prevalence of urinary tract infections in diabetic patients. Rom J Diabetes Nutr Metab Dis., 2013;20(2):99-105.

6. Craig M, A Hattersley, K Donaghue. Chapter 1: Definition, epidemiology, diagnosis and classification. Pediatric Diabetes, 2009;10(Suppl. 12):3-12.

7. Drozdowska A, J Drzewoski. Mycoses in diabetes - difficult diagnostic and therapeutic problem. Review of literature. Diabetoligia, 2008;8(1):1-11.

8. Gow $\mathrm{N}$ et al. Candida albicans morphogenesis and host defence: discriminating invasion from colonization. Nat Rev Microbiol, 2013;10(2):112-122.

9. Grandy S, K Fox, E Hardy. Prevalence and recurrence of urinary tract and genital infections among adults with and without type 2 diabetes mellitus in general population: a longitudinal cohort study. JDRCM, 2013;2(5):1-8.

10. Hostetter MK. Handicaps to host defense. Effects of hyperglycemia on C3 and Candida albicans. Diabetes, 1990;39:271-275.

11. Petrova Ch, B Shentov, S Tanchev et al. Genital infections among girls with type 1 diabetes. Obstet. \& Gynecol., 2004;43(4):21-25.

12. Thomsen R, A Mor. Diabetes and Risk of Community-Acquired respiratory Tract Infections, Urinary Tract Infections, and Bacteremia. The Open Infect. Dis. J., 2012;6(Suppl. 1: M2): 27-39. 